\title{
Numerical study of the burner parameters on the thermal field in a sulfur recovery unit thermal reactor
}

\author{
Chun-Lang Yeh ${ }^{a}$ \\ Department of Aeronautical Engineering, National Formosa University, Taiwan
}

\begin{abstract}
A sulfur recovery unit (SRU) thermal reactor is the most important equipment in a sulfur plant and is negatively affected by high temperature operations. In this paper, the effect of burner parameters, including the clearance of the acid gas tip and the inlet air swirler angle, on the thermal field in a SRU thermal reactor are investigated numerically, with the aim to reduce the high temperature inside the thermal reactor and to ensure an acceptable sulfur recovery. The simulation results show that the burner with a smaller clearance of the acid gas tip produces a lower temperature, a lower exit $\mathrm{SO}_{2}$ mole fraction and higher exit $\mathrm{S}_{2}$ and $\mathrm{H}_{2} \mathrm{~S}$ mole fractions. Among the clearancs of the acid gas tip investigated, the horizontal clearance of $152.4 \mathrm{~mm}$ and vertical clearance of $240 \mathrm{~mm}$ yield the lowest temperature, exit $\mathrm{SO}_{2}$ mole fraction and highest exit $\mathrm{S}_{2}, \mathrm{H}_{2} \mathrm{~S}$ mole fractions. The burner with a smaller inlet air swirler angle produces a higher temperature, a higher exit $\mathrm{SO}_{2}$ mole fraction and lower exit $\mathrm{S}_{2}$ and $\mathrm{H}_{2} \mathrm{~S}$ mole fractions. Among the swirler angles investigated, $60^{\circ}$ yields the lowest temperature, exit $\mathrm{SO}_{2}$ mole fraction and highest exit $\mathrm{S}_{2}, \mathrm{H}_{2} \mathrm{~S}$ mole fractions.
\end{abstract}

\section{Introduction}

Desulfurization is very important in the petroleum refining process because oxysulfides from the petroleum refining process are one of the major sources of air pollution. The most frequently used desulfurization process is the Claus process, which converts the $\mathrm{H}_{2} \mathrm{~S}$ in natural gas or crude oil into sulfur elements and reduces the formation of oxysulfides. A SRU thermal reactor is the most important equipment in a sulfur plant. It converts the $\mathrm{NH}_{3}, \mathrm{H}_{2} \mathrm{~S}$ and hydrocarbons in the reactants into sulfur. Most of the sulfur elements are recovered from the SRU thermal reactor. The first section of a SRU that uses the Claus process is composed of a burner, a thermal reactor and a waste heat exchanger. The configuration and dimensions of the first section of a SRU for a typical petroleum refinery are shown in Fig.1. The inner surface of a SRU thermal reactor is fabricated using a refractory to protect its walls because a SRU thermal reactor operates at very high temperatures. SRU thermal reactors are negatively affected by high temperature operations because high temperature can damage the refractory and the heat exchanger tubes.

\footnotetext{
${ }^{\mathrm{a}}$ Corresponding author : clyeh@nfu.edu.tw

(C) The Authors, published by EDP Sciences. This is an open access article distributed under the terms of the Creative Commons Attribution License 4.0 (http://creativecommons.org/licenses/by/4.0/).
} 


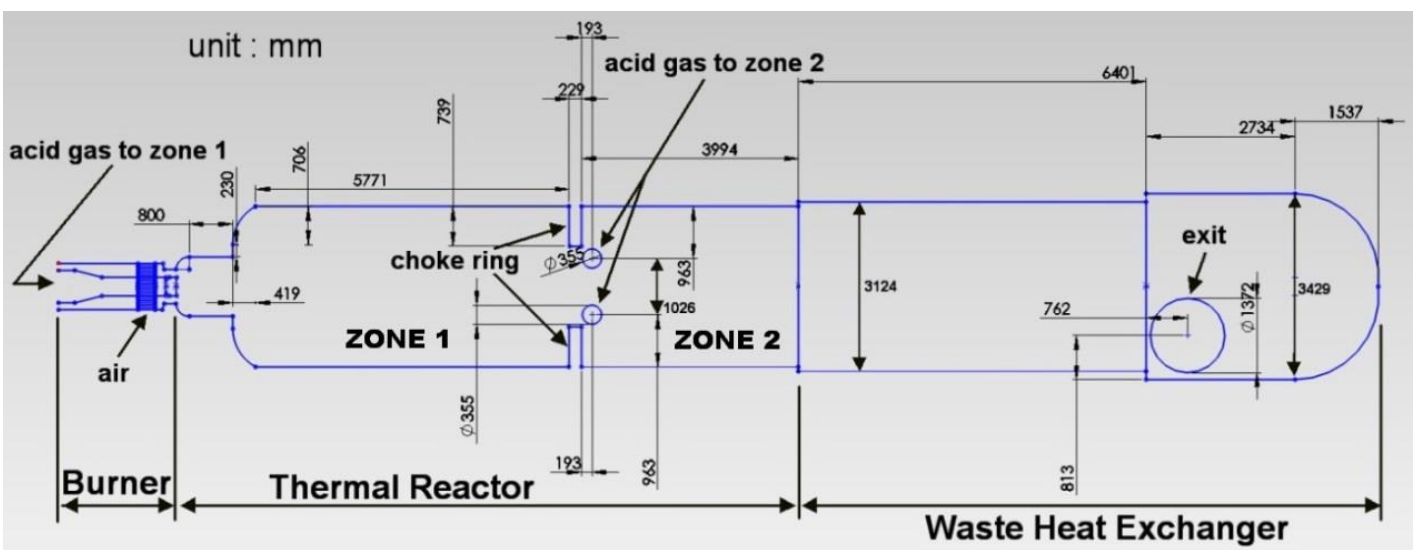

(a) the overall view

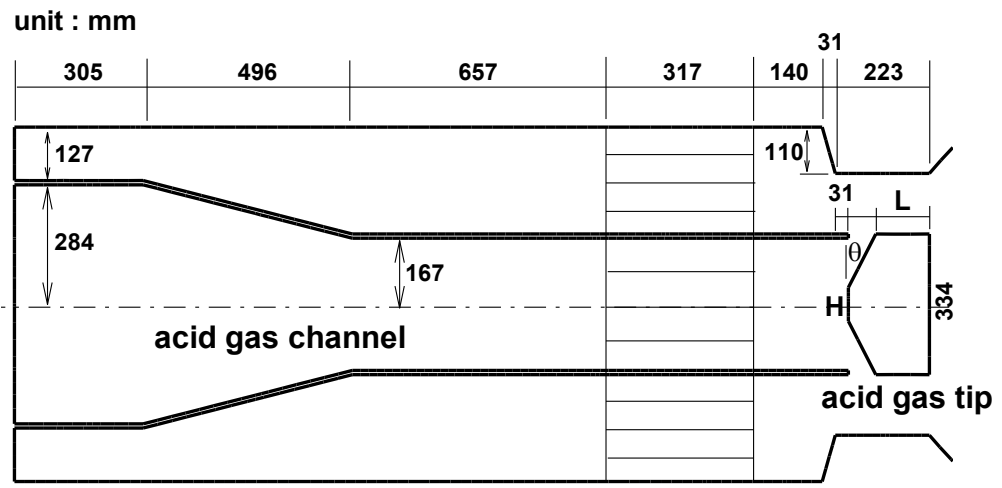

(b) enlarged view for the burner section

Figure 1. The configuration and dimensions of the first section of the SRU for a typical petroleum refinery

There have been theoretical and experimental studies of SRU thermal reactors. Adewale et al. [1] studied the thermal decomposition of $\mathrm{H}_{2} \mathrm{~S}$ into hydrogen and sulfur using a process simulator. Using the net fraction of the acid gas feed to the cracking coils as the controlling parameter, its effect on hydrogen production, the thermal reactor's energy requirement, the stability of the burner flame, steam production, the temperature of a Claus reactor and sulfur recovery of the primary SRU was studied. Chardonneaua et al. [2] presented experimental and simulation results for the addition of various amounts of toluene or carbon dioxide/toluene mixtures into the $\mathrm{H}_{2} \mathrm{~S}$ gas stream. The results show that there is a decrease in conversion efficiency when the amount of toluene or carbon dioxide/toluene added to the $\mathrm{H}_{2} \mathrm{~S}$ gas stream increases. The role of the reactor's operating temperature was also studied. The addition of toluene increases the optimum reactor temperature for enhanced sulfur recovery, but the presence of $\mathrm{CO}_{2}$ reduces the optimum operating temperature. Manenti et al. [3] proposed a kinetic model with 2400 reactions and 140 species and implemented it in a proper reactor network to characterize the thermal reactor and the waste heat exchanger of sulfur recovery units. By doing so, reliable estimation of acid gas conversion, elemental sulfur recovery, and steam generation are achieved with the possibility to carry out an integrated process-energy optimization at the total plant scale. Selim et al. [4] examined the quality of sulfur deposits that were collected from $\mathrm{H}_{2} \mathrm{~S}$ combustion. Sulfur deposits from $\mathrm{H}_{2} \mathrm{~S}$ combustion under various conditions were captured and analyzed using X-ray powder diffraction and laser induced breakdown spectroscopy diagnostics. ZareNezhad and Hosseinpour [5] investigated different alternatives for increasing the reactor temperature of Claus SRUs by chemical equilibrium calculations. They found that the acid gas enrichment is a reliable technique for providing the required reactor temperature when a high flow of too lean acid gas is to be processed in a Claus unit. Monnery et al. [6] experimentally studied the reaction between $\mathrm{H}_{2} \mathrm{~S}$ and $\mathrm{SO}_{2}$ using practical Claus thermal reactor temperatures between 850 and 
$1150^{\circ} \mathrm{C}$ and residence times between 0.05 and 1.2 seconds. The kinetic data obtained were used to develop a new reaction rate expression.

Our experience of operating a practical SRU thermal reactor in Taiwan shows that the refractories at the zone 1 corner and the choke ring are the parts of the thermal reactor that experience the greatest deterioration. The zone 1 corner has a suddenly expanded geometry and a recirculation zone forms behind it. The temperature at the zone 1 corner can exceed the maximum service temperature of the refractory and cause collapse or deformation. The choke ring is subjected to a bending moment from the rapid combustion gas stream and can collapse or deform. Several methods to alleviate this problem have been assessed, including (1) changing the choke ring dimensions [7], (2) changing the choke ring position [8], (3) modifying the geometry of the zone 1 corner to a streamlined geometry $[9,10]$ and (4) replacing the choke ring by a vector wall $[10,11]$. However, these methods are either expensive or require an overhaul of the SRU thermal reactor. In the author's previous studies, two easier and more economical methods, including (1) changing the zone 1 fuel mass fraction [12] and (2) changing the inlet air quantity or the inlet $\mathrm{O}_{2}$ mole fraction [13], were investigated numerically.

In a SRU, most of the acid gas is combusted in the burner which is also supplied with the necessary combustion air. A portion of the acid gas is bypassed around the burner to enter directly into the thermal reactor through nozzles. These nozzles are positioned at the start of the second zone of the thermal reactor. The amount of acid gas bypass is regulated to maintain an acceptable temperature in the first zone. The combustion and fluid flow in the burner has a significant influence on the thermal and fluid flow development in the downstream thermal reactor and heat exchganger. In this paper, the effects of burner parameters, including the clearance of the acid gas tip and the inlet air swirler angle, on the thermal field in a SRU thermal reactor are investigated numerically. The purpose of this study is to reduce the high temperature and to ensure an acceptable sulfur recovery in a thermal reactor. Practical operating conditions from a petrochemical corporation in Taiwan were used as the design conditions for the discussion.

\section{Numerical methods and physical models}

In this study, the FLUENT commercial code is used to simulate the reacting and fluid flow in a SRU thermal reactor. The SIMPLE algorithm by Patankar [14] is used to solve the governing equations. The discretizations of convection terms and diffusion terms are respectively performed using the power-law scheme and the central difference scheme. In terms of physical models, considering the accuracy and stability of the models and the evaluations of other researchers, the standard $k-\varepsilon$ Model [15], the P-1 radiation model [16] and the non-premixed combustion model with $\beta$-type probability density function [17] are respectively used for the turbulence, radiation and combustion simulations. The standard wall functions [18] are used to resolve the flow quantities (velocity, the temperature, and the turbulence quantities) at the near-wall regions. The detailed governing equations and convergence criterion were described in a previous study by the author [19].

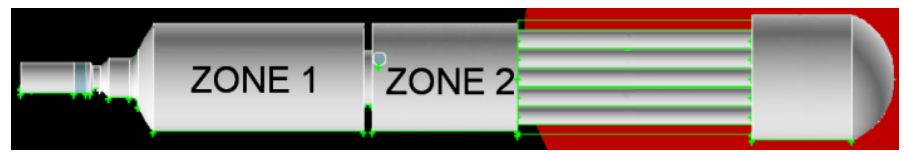

Figure 2. The numerical model for the SRU thermal reactor investigated

In this study, the numerical model of a SRU thermal reactor is constructed using an unstructured grid. Fig.2 shows the numerical model of the SRU thermal reactor investigated. In Fig.2, the heat exchanger section consists of 19 cooling tubes, which have a diameter of $0.5 \mathrm{~m}$, as shown schematically in Fig.3. The heat absorption rate for each heat exchanger tube is $40,000 \mathrm{~W} / \mathrm{m}^{2}$ and the other walls are adiabatic. No slip condition is applied on any of the solid walls. The exit of the heat exchanger section is connected to other equipment at $300 \mathrm{~K}$ and $1 \mathrm{~atm}$ by a pipe that is $1.372 \mathrm{~m}$ in diameter and $11.5 \mathrm{~m}$ in length. 


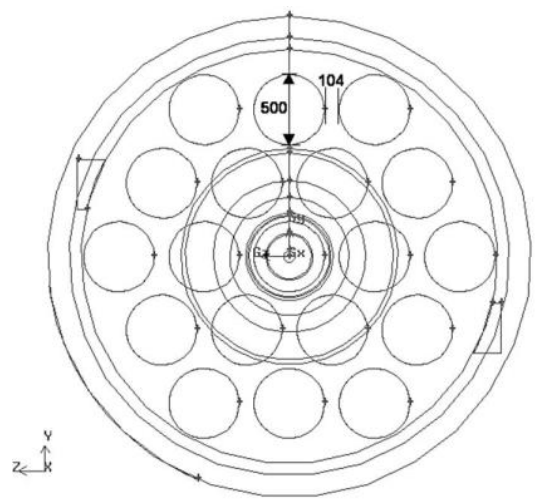

Figure 3. An illustration of the arrangement of heat exchanger tubes

Table 1. The design conditions at the acid gas inlet holes and the air inlet hole

\begin{tabular}{|c|c|c|c|c|c|c|c|c|}
\hline & \multicolumn{4}{|c|}{ Oxygen-normal supply } & \multicolumn{4}{|c|}{ Oxygen-rich supply } \\
\hline species & $\begin{array}{l}\text { Acid gas } \\
\text { to zone } 1\end{array}$ & $\begin{array}{l}\text { Acid gas } \\
\text { to zone } 2\end{array}$ & & ir inlet & $\begin{array}{c}\text { Acid } \\
\text { gas to } \\
\text { zone } 1\end{array}$ & $\begin{array}{c}\text { Acid } \\
\text { gas to } \\
\text { zone } 2\end{array}$ & \multicolumn{2}{|c|}{ Air inlet } \\
\hline $\mathrm{O}_{2}$ & 0 & 0 & & 19.87 & 0 & 0 & \multicolumn{2}{|c|}{23.85} \\
\hline $\mathrm{N}_{2}$ & 0 & 0 & & 74.98 & 0 & 0 & \multicolumn{2}{|c|}{71.26} \\
\hline $\mathrm{H}_{2} \mathrm{O}$ & 7.83 & 4.12 & & 5.15 & 4.12 & 27.97 & \multicolumn{2}{|c|}{4.89} \\
\hline $\mathrm{CO}_{2}$ & 1.27 & 1.5 & & 0 & 1.48 & 0 & \multicolumn{2}{|c|}{0} \\
\hline $\mathrm{H}_{2} \mathrm{~S}$ & 82.06 & 89.88 & & 0 & 89.9 & 39.61 & \multicolumn{2}{|c|}{0} \\
\hline $\mathrm{CH}_{4}$ & 2.28 & 2.7 & & 0 & 2.7 & 0 & \multicolumn{2}{|c|}{0} \\
\hline $\mathrm{C}_{2} \mathrm{H}_{6}$ & 1.52 & 1.8 & & 0 & 1.8 & 0 & \multicolumn{2}{|c|}{0} \\
\hline $\mathrm{NH}_{3}$ & 5.04 & 0 & & 0 & 0 & 32.42 & \multicolumn{2}{|c|}{0} \\
\hline $\mathrm{T}(\mathrm{K})$ & 319.92 & 316.15 & & 03.15 & 313.15 & 316.15 & \multicolumn{2}{|c|}{397.15} \\
\hline $\mathrm{P}\left(\mathrm{N} / \mathrm{m}^{2}\right)$ & 76920 & 75068 & & 74382 & 75068 & 75068 & \multicolumn{2}{|c|}{89572} \\
\hline \multirow{2}{*}{$\mathrm{V}(\mathrm{m} / \mathrm{sec})$} & \multirow{2}{*}{11.62} & \multirow{2}{*}{2.08} & radial & tangential & \multirow{2}{*}{11.46} & \multirow{2}{*}{1.88} & radial & tangential \\
\hline & & & 12.4 & 34.1 & & & 10.8 & 29.8 \\
\hline
\end{tabular}

In this study, two types of oxygen supplies are investigated: an oxygen-normal supply and an oxygen-rich supply. An oxygen-rich supply increases sulfur recovery. The design conditions (including the species compositions, the temperature, the pressure and the velocity) at the acid gas inlet holes of zone 1 and zone 2 and at the air inlet hole are listed in Table 1. These conditions are practical operating conditions that are used by a petrochemical corporation in Taiwan. The turbulence kinetic energy is $10 \%$ of the inlet mean flow kinetic energy and the turbulence dissipation rate is computed using Eq.(1).

$$
\varepsilon=C_{\mu}^{3 / 4} \frac{k^{3 / 2}}{l}
$$

where $l=0.07 \mathrm{~L}$ and $\mathrm{L}$ is the hydraulic diameter.

The grid independence test and validation of the numerical methods have been performed in the author's previous studies mentioned above.

\section{Results and discussion}


To investigate the effects of burner parameters, parametric studies including the clearance of the acid gas tip and the inlet air swirler angle are performed. Their effects on the thermal field in a SRU thermal reactor are investigated numerically.

\subsection{The effect of clearance of the acid gas tip}

Figure 1(b) shows the configuration and dimension of the burner section, from which it is seen that length of the acid gas tip (L) controls the horizontal clearance between the acid gas tip and the acid gas channel. The horizontal clearance decreases with L.

Figure 4 shows a comparison of the cross-sectional average temperatures for SRU thermal reactors with different horizontal clearances of the acid gas tip. The vertical clearance is kept constant by keeping the height of the acid gas tip $(\mathrm{H})$ at $80 \mathrm{~mm}$. Six lengths of the acid gas tip (L) are used and compared, including $25.4 \mathrm{~mm}, 50.8 \mathrm{~mm}, 76.2 \mathrm{~mm}, 101.6 \mathrm{~mm}, 127 \mathrm{~mm}$ and $152.4 \mathrm{~mm}$, among which $127 \mathrm{~mm}$ is the default $\mathrm{L}$ of a petrochemical corporation in Taiwan. It can be observed that a larger horizontal clearance (smaller L) tends to yield a higher temperature. Slower acid gas ejected from the acid gas tip produces a better mixing with the swirling air. In contrast, faster ejected acid gas may retard the mixing with the swirling air. The smallest horizontal clearance $(\mathrm{L}=152.4 \mathrm{~mm})$ leads to the lowest temperature.

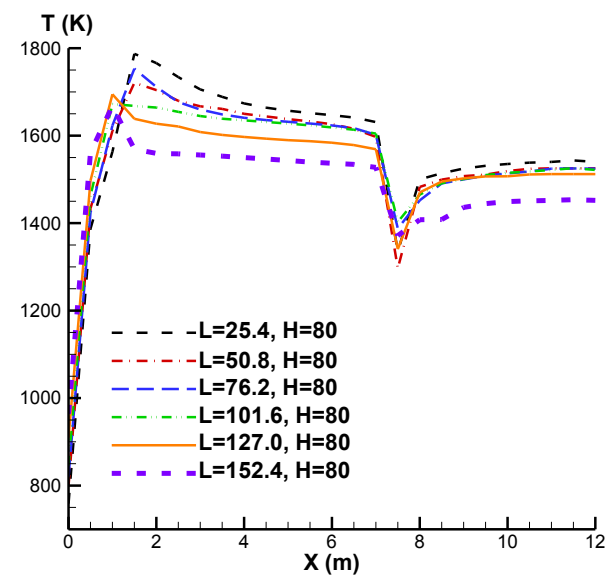

(a) oxygen-normal supply

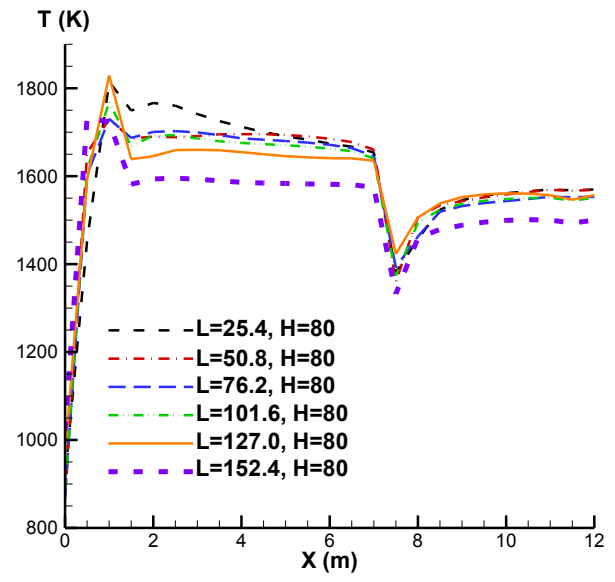

(b) oxygen-rich supply

Figure 4. A comparison of the cross-sectional average temperatures for SRU thermal reactors with different horizontal clearances of the acid gas tip

Figure 5 shows the temperature profiles on the symmetric plane for SRU thermal reactors with different horizontal clearances of the acid gas tip. The zone I average temperature and the exit $\mathrm{S}_{2}, \mathrm{SO}_{2}$ and $\mathrm{H}_{2} \mathrm{~S}$ mole fractions are labelled in the figures, too. It can be observed that a larger horizontal clearance tends to yield a higher zone I average temperature. This is similar to the result of Fig.4. In addition, the exit $\mathrm{SO}_{2}$ mole fraction increases while the exit $\mathrm{S}_{2}$ and $\mathrm{H}_{2} \mathrm{~S}$ mole fractions decrease with the horizontal clearance of the acid gas tip. This is because more $\mathrm{H}_{2} \mathrm{~S}$ is converted to $\mathrm{S}_{2}$ due to the higher temperature when the horizontal clearance of the acid gas tip increases. However, $\mathrm{S}_{2}$ can also react with the air to form $\mathrm{SO}_{2}$ at higher temperatures. The burner with a smaller horizontal clearance of the acid gas tip produces a lower temperature, a lower exit $\mathrm{SO}_{2}$ mole fraction and higher exit $\mathrm{S}_{2}$ and $\mathrm{H}_{2} \mathrm{~S}$ mole fractions. Among the horizontal clearancs of the acid gas tip investigated, $\mathrm{L}=152.4 \mathrm{~mm}$ yields the lowest temperature, exit $\mathrm{SO}_{2}$ mole fraction and highest exit $\mathrm{S}_{2}, \mathrm{H}_{2} \mathrm{~S}$ mole fractions. 


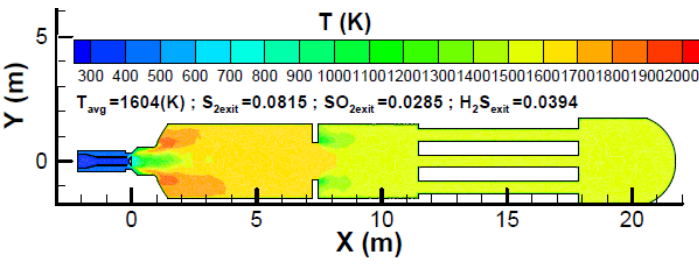

(a) $\mathrm{L}=25.4 \mathrm{~mm}, \mathrm{H}=80 \mathrm{~mm}$, oxygen-normal supply

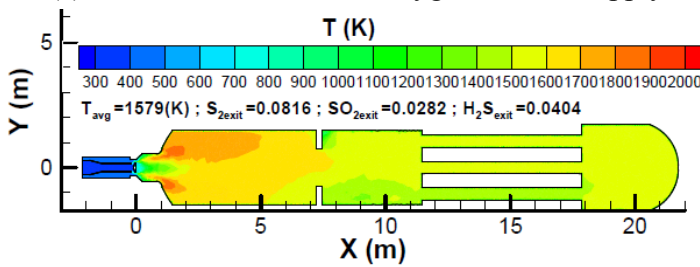

(c) $\mathrm{L}=50.8 \mathrm{~mm}, \mathrm{H}=80 \mathrm{~mm}$, oxygen-normal supply

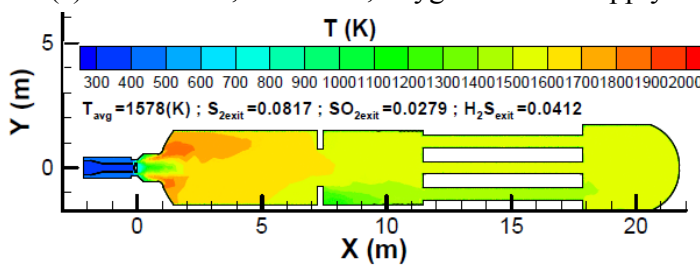

(e) $\mathrm{L}=76.2 \mathrm{~mm}, \mathrm{H}=80 \mathrm{~mm}$, oxygen-normal supply

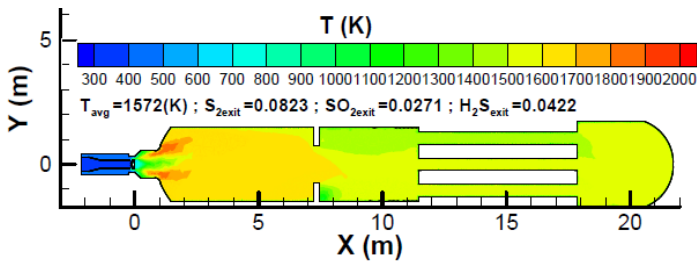

(g) $\mathrm{L}=101.6 \mathrm{~mm}, \mathrm{H}=80 \mathrm{~mm}$, oxygen-normal supply

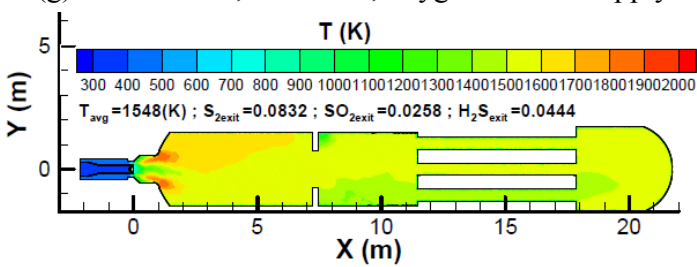

(i) $\mathrm{L}=127 \mathrm{~mm}, \mathrm{H}=80 \mathrm{~mm}$, oxygen-normal supply

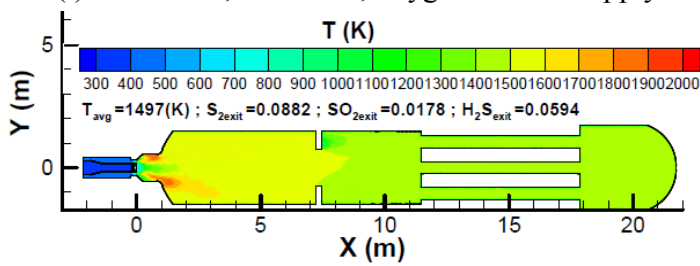

(k) $\mathrm{L}=152.4 \mathrm{~mm}, \mathrm{H}=80 \mathrm{~mm}$, oxygen-normal supply

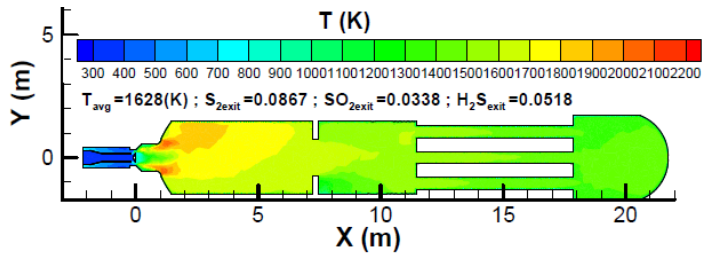

(b) $\mathrm{L}=25.4 \mathrm{~mm}, \mathrm{H}=80 \mathrm{~mm}$, oxygen-rich supply

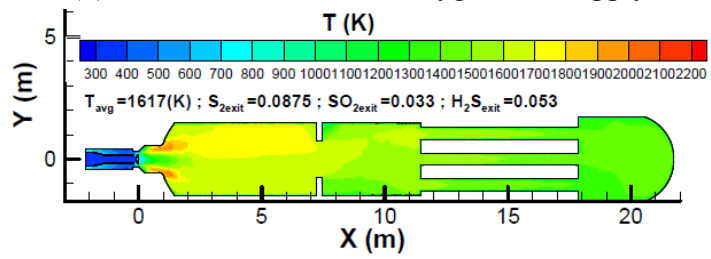

(d) $\mathrm{L}=50.8 \mathrm{~mm}, \mathrm{H}=80 \mathrm{~mm}$, oxygen-rich supply

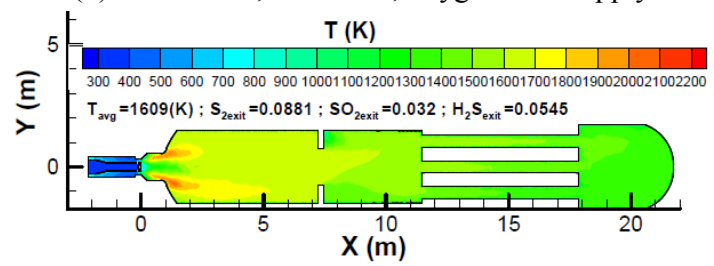

(f) $\mathrm{L}=76.2 \mathrm{~mm}, \mathrm{H}=80 \mathrm{~mm}$, oxygen-rich supply

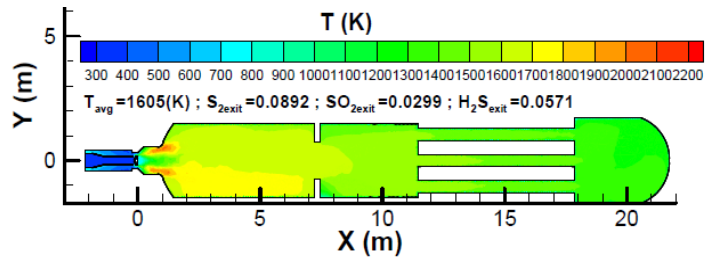

(h) $\mathrm{L}=101.6 \mathrm{~mm}, \mathrm{H}=80 \mathrm{~mm}$, oxygen-rich supply

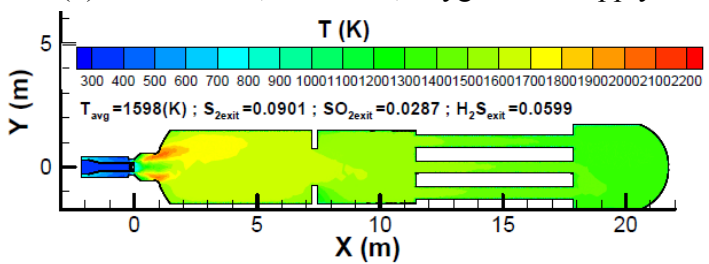

(j) $\mathrm{L}=127 \mathrm{~mm}, \mathrm{H}=80 \mathrm{~mm}$, oxygen-rich supply

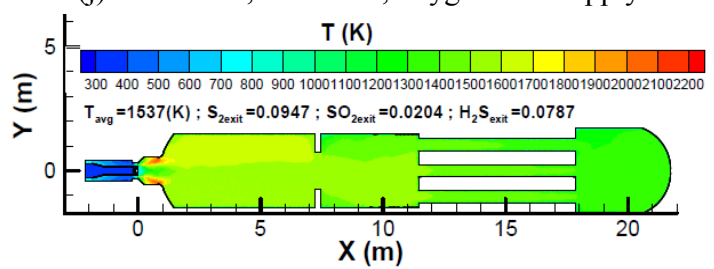

(1) $\mathrm{L}=152.4 \mathrm{~mm}, \mathrm{H}=80 \mathrm{~mm}$, oxygen-rich supply

Figure 5. The temperature profiles on the symmetric plane for SRU thermal reactors with different horizontal clearances of the acid gas tip

In Fig.1(b), the height of the acid gas tip $(\mathrm{H})$ controls the vertical clearance of the acid gas tip. The vertical clearance decreases with $\mathrm{H}$. Figure 6 shows a comparison of the cross-sectional average temperatures for SRU thermal reactors with different vertical clearancs of the acid gas tip. The horizontal clearance is kept constant by keeping the length of the acid gas tip (L) at $127 \mathrm{~mm}$. Four hights of the acid gas tip $(\mathrm{H})$ are used and compared, including $40 \mathrm{~mm}, 80 \mathrm{~mm}, 160 \mathrm{~mm}$ and $240 \mathrm{~mm}$, 
among which $80 \mathrm{~mm}$ is the default $\mathrm{H}$ of a petrochemical corporation in Taiwan. It can be observed that a larger vertical clearance (smaller $\mathrm{H}$ ) tends to yield a higher temperature. This result is similar to that of a larger horizontal clearance. The smallest vertical clearance $(\mathrm{H}=240 \mathrm{~mm})$ leads to the lowest temperature.

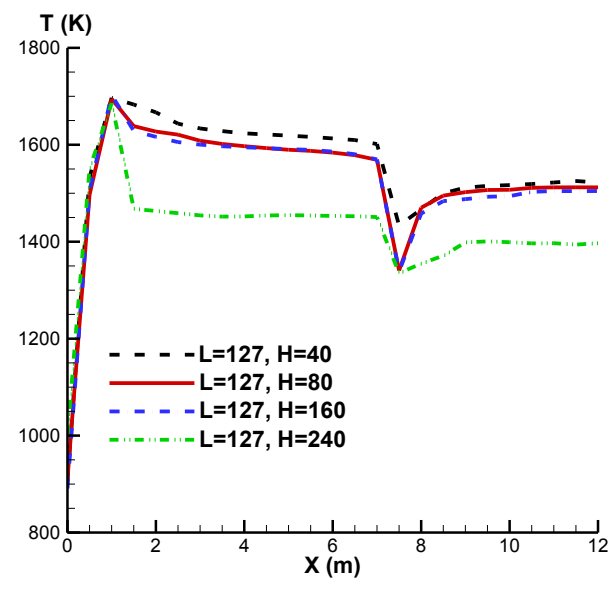

(a) oxygen-normal supply

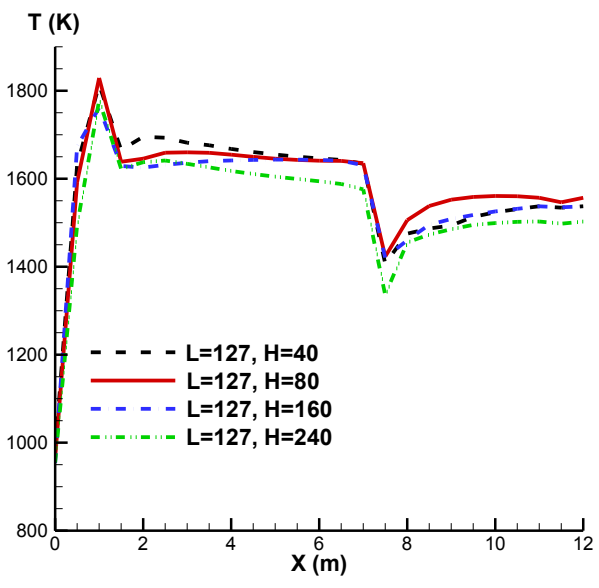

(b) oxygen-rich supply

Figure 6. A comparison of the cross-sectional average temperatures for a SRU thermal reactor with different vertical clearances of the acid gas tip

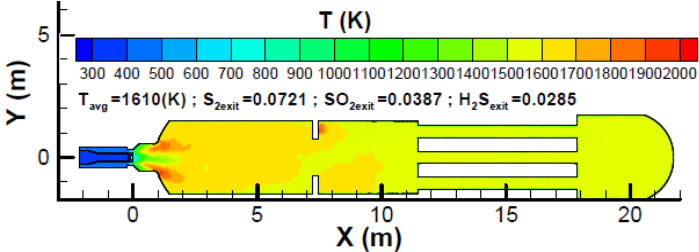

(a) $\mathrm{L}=127 \mathrm{~mm}, \mathrm{H}=40 \mathrm{~mm}$, oxygen-normal supply

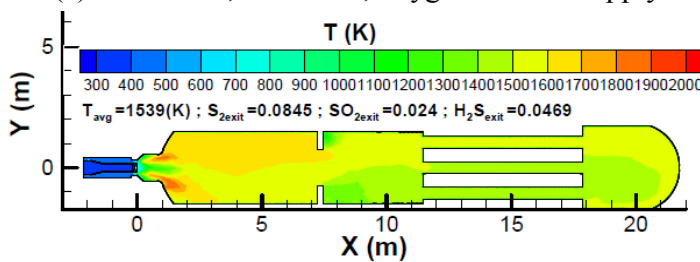

(c) $\mathrm{L}=127 \mathrm{~mm}, \mathrm{H}=160 \mathrm{~mm}$, oxygen-normal supply

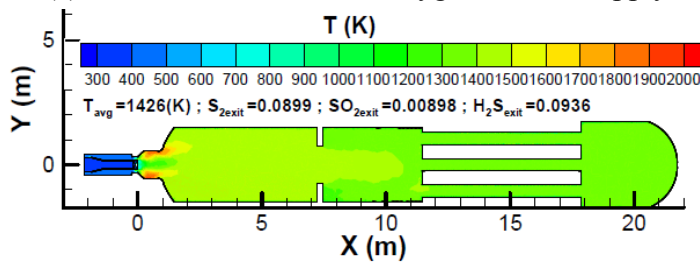

(e) $\mathrm{L}=127 \mathrm{~mm}, \mathrm{H}=240 \mathrm{~mm}$, oxygen-normal supply

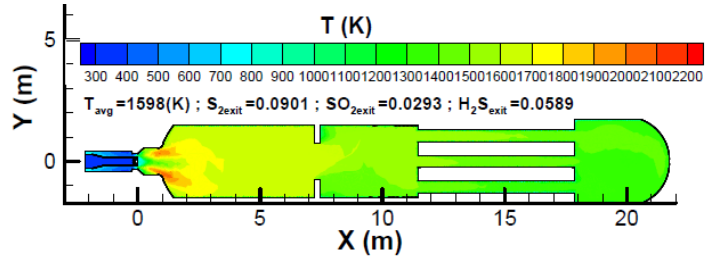

(b) $\mathrm{L}=127 \mathrm{~mm}, \mathrm{H}=40 \mathrm{~mm}$, oxygen-rich supply

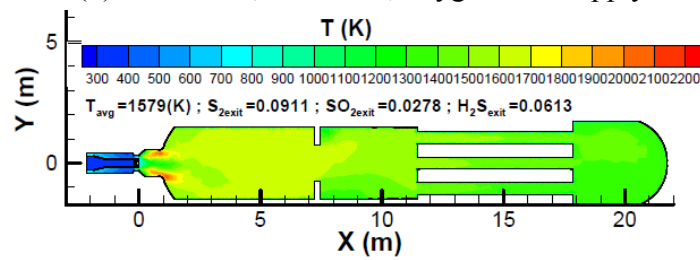

(d) $\mathrm{L}=127 \mathrm{~mm}, \mathrm{H}=160 \mathrm{~mm}$, oxygen-rich supply

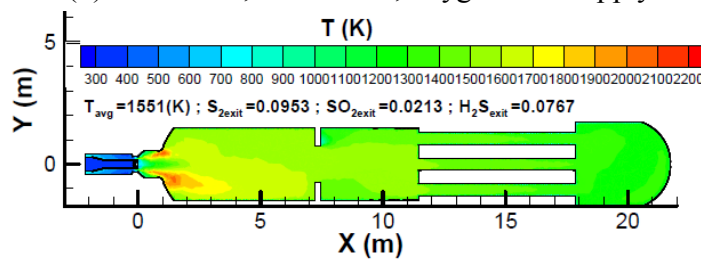

(f) $\mathrm{L}=127 \mathrm{~mm}, \mathrm{H}=240 \mathrm{~mm}$, oxygen-rich supply

Figure 7. The temperature profiles on the symmetric plane for SRU thermal reactors with different vertical clearancs of the acid gas tip

Figure 7 shows the temperature profiles for SRU thermal reactors with different vertical clearancs of the acid gas tip. Note that the case of $\mathrm{L}=127 \mathrm{~mm}$ and $\mathrm{H}=80 \mathrm{~mm}$ has been shown in Figs.5(i) and (j). It can be observed that a larger vertical clearance of the acid gas tip tends to yield a higher zone I average temperature. This is similar to the result of Fig.6. In addition, the exit $\mathrm{SO}_{2}$ mole fraction 
increases while the exit $\mathrm{S}_{2}$ and $\mathrm{H}_{2} \mathrm{~S}$ mole fractions decrease with the vertical clearance of the acid gas tip. This is similar to the result of Fig.5. From the results of Figs. 5 and 7, the burner with a smaller clearance of the acid gas tip produces a lower temperature, a lower exit $\mathrm{SO}_{2}$ mole fraction and higher exit $\mathrm{S}_{2}$ and $\mathrm{H}_{2} \mathrm{~S}$ mole fractions. Among the vertical clearancs of the acid gas tip investigated, $\mathrm{H}=240 \mathrm{~mm}$ yields the lowest temperature, exit $\mathrm{SO}_{2}$ mole fraction and highest exit $\mathrm{S}_{2}, \mathrm{H}_{2} \mathrm{~S}$ mole fractions.

\subsection{The effect of air swirler angle}

The inlet air swirler angle, $\theta_{\mathrm{sw}}$, controls the strength of the swirling motion. The swirling strength can be expressed in terms of the the radial $\left(v_{r}\right)$ and tangential $\left(v_{\theta}\right)$ components of the inlet air velocity by the following equation.

$$
v_{r} / v_{\theta}=\tan \theta_{\mathrm{sw}}
$$

A smaller $\theta_{\mathrm{sw}}$ corresponds to a stronger swirling motion.

Figure 8 shows a comparison of the cross-sectional average temperatures for SRU thermal reactors with different inlet air swirler angles. The length $(\mathrm{L})$ and height $(\mathrm{H})$ of the acid gas tip are kept at $127 \mathrm{~mm}$ and $80 \mathrm{~mm}$, respectively. Four inlet air swirler angles $\left(\theta_{\mathrm{sw}}\right)$ are used and compared, including $10^{\circ}, 20^{\circ}, 30^{\circ}$ and $60^{\circ}$. It can be observed that a smaller $\theta_{\text {sw }}$ tends to yield a higher zone I temperature. This is because a stronger swirling motion leads to a better mixing, a more complete chemical reaction and hence a higher temperature. The smallest $\theta_{\mathrm{sw}}\left(10^{\circ}\right)$ produces the highest zone I temperature.

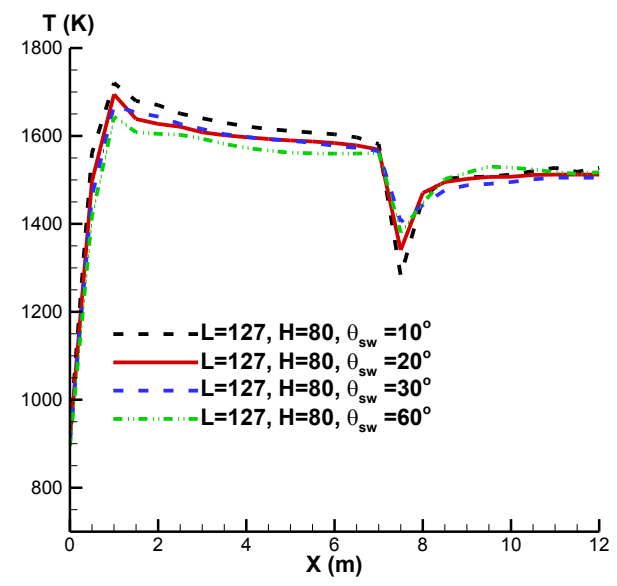

(a) oxygen-normal supply

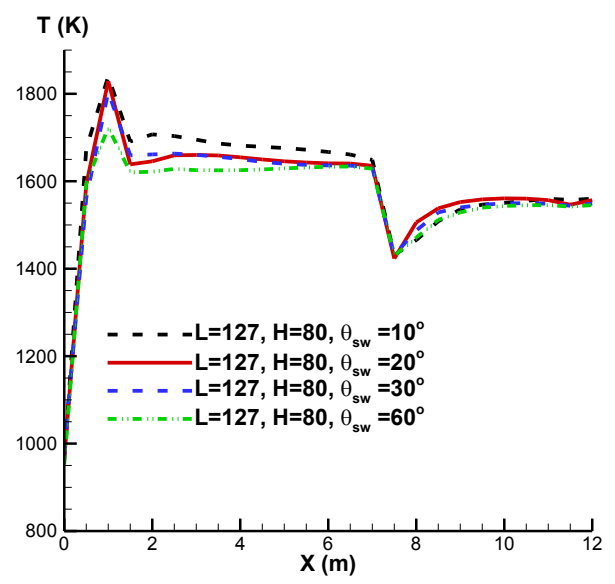

(b) oxygen-rich supply

Figure 8. A comparison of the cross-sectional average temperatures for SRU thermal reactors with different inlet air swirler angles

Figure 9 shows the temperature profiles for SRU thermal reactors with different inlet air swirler angles. Note that the case of $\theta_{\mathrm{sw}}=20^{\circ}$ has been shown in Figs.5(i) and (j). It can be observed that a smaller $\theta_{\text {sw }}$ tends to yield a higher zone I average temperature. This is similar to the result of Fig.8. In addition, for a smaller $\theta_{\text {sw }}$, the exit $\mathrm{S}_{2}$ and $\mathrm{H}_{2} \mathrm{~S}$ mole fractions are lower while the exit $\mathrm{SO}_{2}$ mole fraction is higher. This is because more $\mathrm{H}_{2} \mathrm{~S}$ is converted to $\mathrm{S}_{2}$ due to the higher temperature when $\theta_{\text {sw }}$ is smaller. However, $\mathrm{S}_{2}$ can also react with air to form $\mathrm{SO}_{2}$ at a higher temperature. The burner with a smaller $\theta_{\text {sw }}$ produces a higher temperature, a higher exit $\mathrm{SO}_{2}$ mole fraction and lower exit $\mathrm{S}_{2}$ and $\mathrm{H}_{2} \mathrm{~S}$ mole fractions. Among the swirler angles investigated, $\theta_{\mathrm{sw}}=60^{\circ}$ yields the lowest temperature, exit $\mathrm{SO}_{2}$ mole fraction and highest exit $\mathrm{S}_{2}, \mathrm{H}_{2} \mathrm{~S}$ mole fractions. 


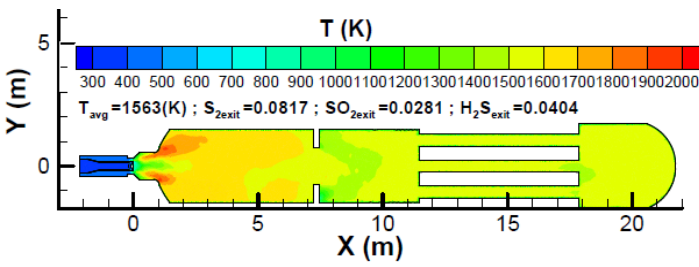

(a) $\mathrm{L}=127 \mathrm{~mm}, \mathrm{H}=80 \mathrm{~mm}, \theta_{\mathrm{sw}}=10^{\circ}$, oxygen-normal

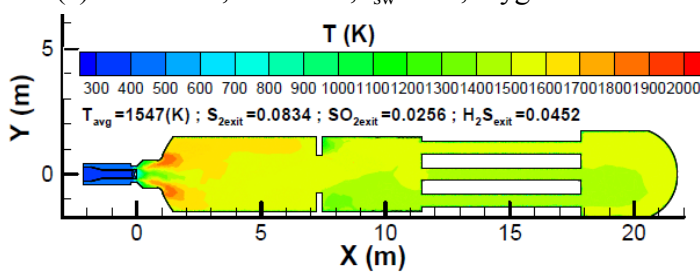

(c) $\mathrm{L}=127 \mathrm{~mm}, \mathrm{H}=80 \mathrm{~mm}, \theta_{\mathrm{sw}}=30^{\circ}$, oxygen-normal

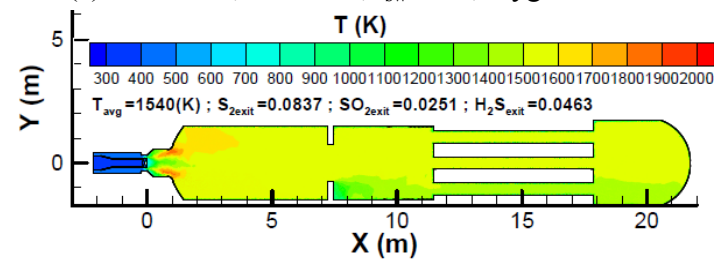

(e) $\mathrm{L}=127 \mathrm{~mm}, \mathrm{H}=80 \mathrm{~mm}, \theta_{\mathrm{sw}}=60^{\circ}$, oxygen-normal

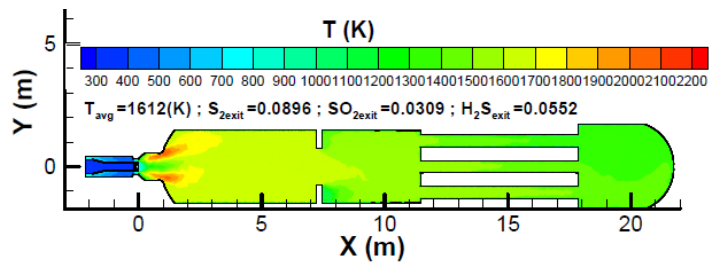

(b) $\mathrm{L}=127 \mathrm{~mm}, \mathrm{H}=80 \mathrm{~mm}, \theta_{\mathrm{sw}}=10^{\circ}$, oxygen-rich

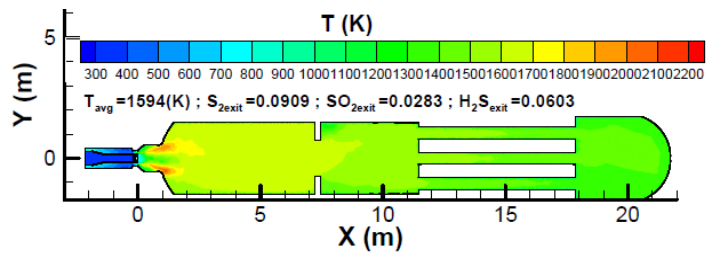

(d) $\mathrm{L}=127 \mathrm{~mm}, \mathrm{H}=80 \mathrm{~mm}, \theta_{\mathrm{sw}}=30^{\circ}$, oxygen-rich

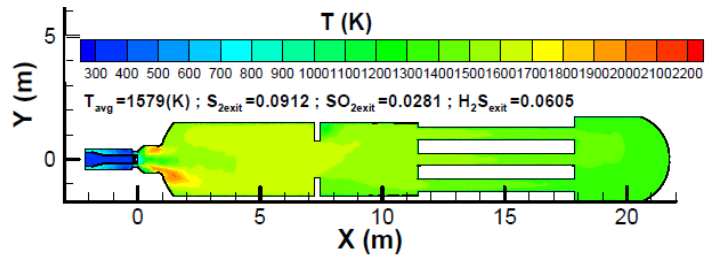

(f) $\mathrm{L}=127 \mathrm{~mm}, \mathrm{H}=80 \mathrm{~mm}, \theta_{\mathrm{sw}}=60^{\circ}$,oxygen-rich

Figure 9. The temperature profiles on the symmetric plane for SRU thermal reactors with different inlet air swirler angles

\section{Conclusion}

This paper numerically investigates the the effect of burner parameters, including the clearance of the acid gas tip and the inlet air swirler angle, on the thermal field in a SRU thermal reactor, in order to reduce the high temperature inside the thermal reactor and to ensure an acceptable sulfur recovery. Practical operating conditions for a petrochemical corporation in Taiwan are used as the design conditions. The simulation results show that the burner with a smaller clearance of the acid gas tip produces a lower temperature, a lower exit $\mathrm{SO}_{2}$ mole fraction and higher exit $\mathrm{S}_{2}$ and $\mathrm{H}_{2} \mathrm{~S}$ mole fractions. Among the clearancs of the acid gas tip investigated, the horizontal clearance of $152.4 \mathrm{~mm}$ and vertical clearance of $240 \mathrm{~mm}$ yield the lowest temperature, exit $\mathrm{SO}_{2}$ mole fraction and highest exit $\mathrm{S}_{2}, \mathrm{H}_{2} \mathrm{~S}$ mole fractions. The burner with a smaller inlet air swirler angle produces a higher temperature, a higher exit $\mathrm{SO}_{2}$ mole fraction and lower exit $\mathrm{S}_{2}$ and $\mathrm{H}_{2} \mathrm{~S}$ mole fractions. Among the swirler angles investigated, $60^{\circ}$ yields the lowest temperature, exit $\mathrm{SO}_{2}$ mole fraction and highest exit $\mathrm{S}_{2}, \mathrm{H}_{2} \mathrm{~S}$ mole fractions.

\section{Acknowledgements}

The author gratefully acknowledges the grant support from the Ministry of Science and Technology, Taiwan, R.O.C., under contract MOST 105-2221-E-150-021.

\section{References}

1. R. Adewale, D.J. Salem, A.S. Berrouk and S. Dara, J. Clean Prod., 112, 4815 (2016)

2. M. Chardonneaua, S. Ibrahim, A.K. Gupta and A. AlShoaibi, Energy Procedia, 75, 3071 (2015)

3. F. Manenti, D. Papasidero, G. Bozzano and E. Ranzi, Comput. Chem. Eng., 66, 244 (2014) 
4. H. Selim, A.K. Gupta and A. AlShoaibi, Appl. Energy, 104, 772 (2013)

5. B. ZareNezhad and N. Hosseinpour, Appl. Therm. Eng., 28, 738 (2008)

6. W.D. Monnery, K.A. Hawboldt, A. Pollock and W.Y. Svrcek, Chem. Eng. Sci., 55, 5141 (2000)

7. C.L.Yeh, T. Can. Soc. Mech. Eng., 40(4), 511 (2016)

8. C.L. Yeh, Int. J. Mech. Eng. Rob. Res., 4(3), 273 (2015)

9. C.L.Yeh, The International Multi-Conference on Engineering and Technology Innovation 2015, J5043 (2015)

10. C.L. Yeh, T. Can. Soc. Mech. Eng., 40(5), 811 (2016)

11. C.L.Yeh, The International Multi-Conference on Engineering and Technology Innovation 2015, J5042 (2015)

12. C.L. Yeh, Appl. Sci., 6(11), 331 (2016)

13. C.L. Yeh, T. Can. Soc. Mech. Eng., 41(2), 293 (2017)

14. S.V. Patankar, Numerical heat transfer and fluid flows (New York: McGraw-Hill,1980)

15. B.E. Launder and D.B. Spalding, Lectures in mathematical models of turbulence (London England: Academic press, 1972)

16. R. Siegel and J.R. Howell, Thermal radiation heat transfe (Washington DC: Hemisphere publishing corporation; 1992)

17. Y.R. Sivathanu and G.M. Faeth, Combust. Flame, 82, 211 (1990)

18. B.E. Launder and D.B. Spalding, Comput. Method Appl. Mech. Eng., 3(2), 269 (1974)

19. C.L. Yeh, Int. J. Heat Mass Tran., 59, 172 (2013) 